\title{
Trends in coronary heart disease in two Belgian areas: results from the MONICA Ghent-Charleroi study
}

\author{
Stefaan De Henauw, Dirk De Bacquer, Patrick de Smet, Marcel Kornitzer, Guy De Backer
}

\begin{abstract}
Setting-As part of the WHO-MONICA study, acute coronary events have been registered from 1983 until 1992 in the general population aged 25-69 years in two Belgian cities-Ghent in the northern Dutch speaking part of Belgium and Charleroi in the southern French speaking part. Registration of events was done according to an international standard protocol.
\end{abstract}

Objective-To study trends in total, fatal and non-fatal event rates and trends in case fatality rates in these two cities.

Main results-Incidence of CHD was on average $50 \%$ higher in Charleroi compared with Ghent in both men and women (attack rate ratio Charleroi/Ghent was 1.5 in both sexes). In both men and women, diverging trends were observed between the two cities for total and non-fatal event rates, while parallel declining trends were observed in fatal event rates and in case fatality rates. In both sexes, total attack rates showed a significant decrease in Ghent and a significant increase in Charleroi. Also in the two sexes, attack rates of non-fatal events increased significantly in Charleroi and remained stable in Ghent. Attack rates of fatal events decreased significantly in men and women in Ghent and in men in Charleroi. Both "total" and "in hospital" case fatality rates declined significantly in both sexes in the two cities. Conclusions-Important differences in coronary heart disease (CHD) incidence and CHD trends between Ghent and Charleroi were observed. These differcontext of existing and still growing differences in the overall socioeconomic situation between the north and the south of the country. On the other hand, the efficacy of medical treatment of CHD is comparable in the two regions, as reflected by similar figures and trends for case fatality rates.

(F Epidemiol Community Health 1999;53:89-98)

P de Smet

M Kornitze

Correspondence to: Dr S De Henauw,

Department of Public

Health, University Hospita

2BlokA, De Pintelaan 185

9000 Ghent, Belgium.

Accepted for publication 7 July 1998

Between countries, diverging trends in coronary heart disease (CHD) mortality have been reported over the past decades, mostly on the basis of the available national or regional routine mortality statistics. ${ }^{1-15}$ According to these statistics, Belgium has experienced a very significant decline in CHD mortality over the ences and trends are interpreted in the

past 25 years and the reasons for this are only poorly understood..$^{15}$

Trends in CHD mortality statistics show however only one dimension of the occurrence of the disease and are in itself the resultant of changes in incidence rates and possible changes in case fatality of the disease, which is in turn determined by potential changes in the natural history of the disease and the available medical care. As an example, declining CHD mortality trends could be a result of increasing CHD incidence accompanied by a more rapidly decreasing case fatality rate because of a more aggressive and efficient treatment in the acute phase of the event.

An additional problem in the context of international comparisons is that the quality of vital statistics seems to show large variability across countries and-within countriesacross time, across disease groups, across age groups, etc. ${ }^{16-19}$

During the seventies, it was largely recognised that valid mortality data along with morbidity data for CHD were required to understand fully the impact of the disease on public health. For this purpose, the World Health Organisation (WHO) has convened experts from countries worldwide and has launched a large epidemiological project in the eighties, known as the WHO-MONICA project (Multinational Monitoring of Trends and Determinants in Cardiovascular Diseases), in which trends in CHD and in coronary risk factors are monitored in 26 countries according to a standardised protocol. Belgium was particularly interested in joining this project, given the already mentioned favourable trends in official mortality statistics for CHD in Belgium and given also the known important differences in CHD mortality and in risk factors between the two constituting different cultural entitiesFlanders in the north and Wallonia in the south of Belgium. ${ }^{20-24}$

In this paper, 10 year trends in fatal and non-fatal acute coronary events and in case fatality rates are presented for the two reporting units of the Belgian MONICA Collaborating Centre Ghent-Charleroi.

\section{Methods}

Although Belgium is one of the smallest countries in Europe, it is divided into two different communities-Flanders in the north and Wallonia in the south - with different languages (respectively Dutch and French) and with considerable differences in cultural background. The cities of Ghent and Charleroi are two pro- 
Table 1 Proportional distribution of acute coronary events across the different MONICA diagnostic categories

\begin{tabular}{|c|c|c|c|c|c|c|c|c|}
\hline & \multicolumn{4}{|l|}{ Ghent } & \multicolumn{4}{|l|}{ Charleroi } \\
\hline & \multicolumn{2}{|l|}{ Men } & \multicolumn{2}{|l|}{ Women } & \multicolumn{2}{|l|}{ Men } & \multicolumn{2}{|l|}{ Women } \\
\hline & $\begin{array}{l}\text { Non-fatal } \\
n(\%)\end{array}$ & $\begin{array}{l}\text { Fatal } \\
n(\%)\end{array}$ & $\begin{array}{l}\text { Non-fatal } \\
n(\%)\end{array}$ & $\begin{array}{l}\text { Fatal } \\
n(\%)\end{array}$ & $\begin{array}{l}\text { Non-fatal } \\
n(\%)\end{array}$ & $\begin{array}{l}\text { Fatal } \\
n(\%)\end{array}$ & $\begin{array}{l}\text { Non-fatal } \\
n(\%)\end{array}$ & $\begin{array}{l}\text { Fatal } \\
n(\%)\end{array}$ \\
\hline Definite events & $1060(81.7)$ & $147(12.8)$ & $256(72.5)$ & $62(14.3)$ & $1299(76.0)$ & $179(12.5)$ & $363(69.7)$ & $67(12.3)$ \\
\hline Possible events & $223(17.2)$ & $502(43.8)$ & $91(25.8)$ & $167(38.4)$ & 403 (23.6) & $660(46.2)$ & $157(30.1)$ & $218(40.1)$ \\
\hline Ischaemic cardiac arrest & $15(1.2)$ & - & $6(1.7)$ & - & $6(0.4)$ & - & $1(0.2)$ & - \\
\hline Fatal events with insufficient data & - & 496 (43.3) & - & $206(47.4)$ & - & $589(41.2)$ & - & $258(47.5)$ \\
\hline Total & 1298 & 1145 & 353 & 435 & 1708 & 1428 & 521 & 543 \\
\hline Total $(\mathrm{NF}+\mathrm{F})$ & 2443 & & 788 & & 3136 & & 1064 & \\
\hline
\end{tabular}

Table 2 Age standardised attack rates (10 000) over a 10 year period, by reporting unit and by sex: all acute coronary events, non-fatal events, and fatal events

\begin{tabular}{|c|c|c|c|c|c|c|c|c|c|c|c|c|}
\hline & \multicolumn{6}{|l|}{ Ghent } & \multicolumn{6}{|c|}{ Charleroi } \\
\hline & \multicolumn{3}{|l|}{ Men } & \multicolumn{3}{|l|}{ Women } & \multicolumn{3}{|l|}{ Men } & \multicolumn{3}{|l|}{ Women } \\
\hline & $F+N F$ & $N F$ & $F$ & $F+N F$ & $N F$ & $F$ & $F+N F$ & $N F$ & $F$ & $F+N F$ & $N F$ & $F$ \\
\hline 1983 & 39.8 & 17.5 & 22.3 & 11.9 & 4.1 & 7.8 & 48.5 & 24.4 & 24.1 & 15.6 & 6.9 & 8.7 \\
\hline 1984 & 40.9 & 21.4 & 19.6 & 16.1 & 6.1 & 10.0 & 43.9 & 19.7 & 24.2 & 13.7 & 4.7 & 9.0 \\
\hline 1985 & 34.6 & 17.6 & 17.0 & 11.5 & 3.8 & 7.7 & 44.4 & 19.4 & 25.0 & 13.0 & 5.7 & 7.3 \\
\hline 1986 & 38.5 & 20.4 & 18.1 & 12.1 & 6.0 & 6.1 & 53.3 & 25.8 & 27.4 & 15.4 & 5.6 & 9.8 \\
\hline 1987 & 41.8 & 23.2 & 18.6 & 9.0 & 5.7 & 3.3 & 52.2 & 23.8 & 28.4 & 15.8 & 6.1 & 9.6 \\
\hline 1988 & 34.6 & 18.2 & 16.3 & 10.0 & 4.4 & 5.6 & 57.5 & 35.5 & 22.0 & 18.8 & 9.5 & 9.3 \\
\hline 1989 & 36.1 & 22.2 & 13.9 & 10.1 & 4.7 & 5.4 & 54.1 & 33.9 & 20.2 & 18.3 & 10.7 & 7.7 \\
\hline 1990 & 32.0 & 17.7 & 14.2 & 10.4 & 5.7 & 4.7 & 54.8 & 31.8 & 23.0 & 18.3 & 9.6 & 8.7 \\
\hline 1991 & 33.6 & 18.5 & 15.1 & 10.6 & 5.2 & 5.4 & 60.1 & 38.0 & 22.1 & 18.3 & 10.8 & 7.5 \\
\hline 1992 & 35.5 & 18.8 & 16.7 & 10.1 & 4.6 & 5.4 & 50.3 & 30.2 & 20.1 & 17.1 & 10.1 & 6.9 \\
\hline
\end{tabular}

F: fatal; NF: non-fatal.

vincial cities of comparable size $( \pm 250000$ inhabitants in Ghent and in Charleroi), geographically situated on both sides of the linguistic frontier (Ghent in Flanders and Charleroi in Wallonia) at a distance of approximately 100 kilometres from each other. In the MONICA jargon, the cities of Ghent and Charleroi are called "reporting units", while both cities together form a so called MONICA Collaborating Centre.

The target population for the GhentCharleroi MONICA acute coronary event register were all inhabitants in these two cities aged 25-69 years (the numbers ranged from 130958 and 118162 in 1983 to 127755 and

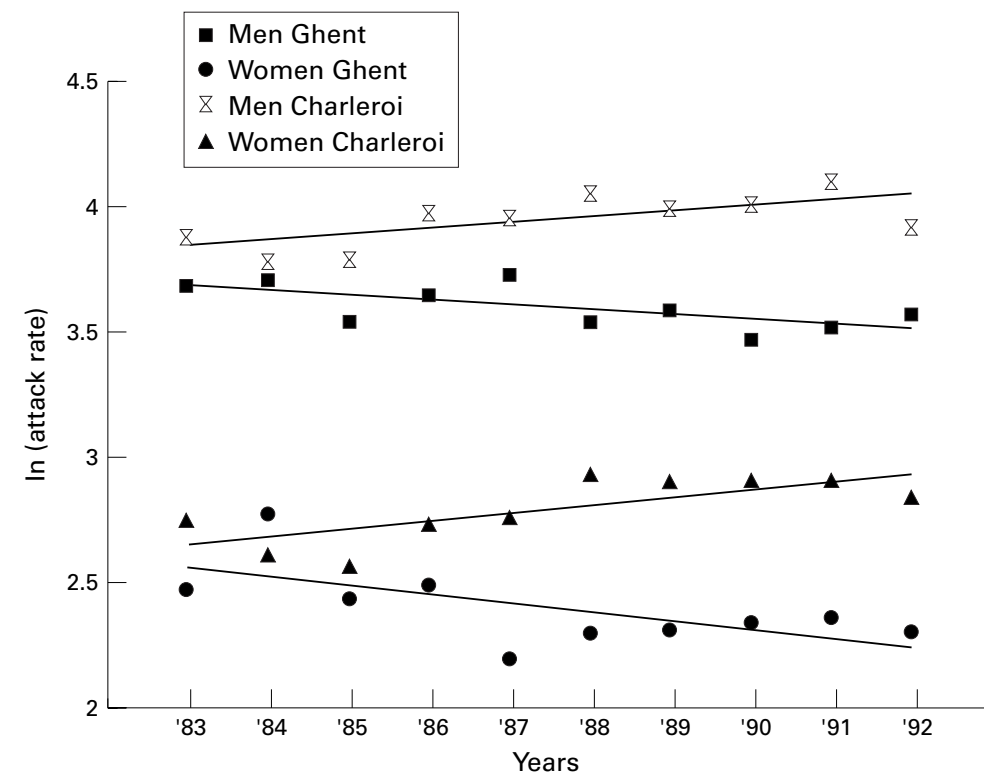

Figure 1 Trends in attack rates of all (fatal and non-fatal) acute coronary events over a 10 year period (1983-1992) by reporting unit and by sex.
120659 in 1992 in Ghent and Charleroi respectively).

In this paper, results of the acute coronary event registration over a 10 year period (1983 to 1992) are reported.

Collaboration for the case finding was obtained from the official death registration services in Ghent and Charleroi, from all hospitals and medical doctors working in both regions.

All "acute medical events" were systematically subjected to a routine standardised thorough case ascertainment procedure. For out of hospital fatal cases, the death certificate was used as starting point for tracing further medical background information from the patient's family doctor, the doctor who had certified death and/or the emergency team that in some cases attended the acute phase of the event. For fatal and non-fatal hospitalised cases, hospital records were studied and-if necessary-additional information was obtained from the family doctor; sporadic cases of non-hospitalised non-fatal cases were traced and investigated with the help of the general practitioners in both regions.

The criteria and procedures that are used in MONICA to categorise acute events in different diagnostic categories have been published. ${ }^{25} 26$ Briefly, data on the clinical picture in the acute phase of the event, on electrocardiographic changes, on serum enzymes, on medical antecedents, and on necropsy were, if available, used to classify every suspected acute coronary event in one of the following mutually exclusive categories: no acute myocardial infarction (AMI); definite AMI; probable AMI; ischaemic cardiac arrest, successfully resuscitated (for non-fatal events only); fatal cases with insufficient data. 


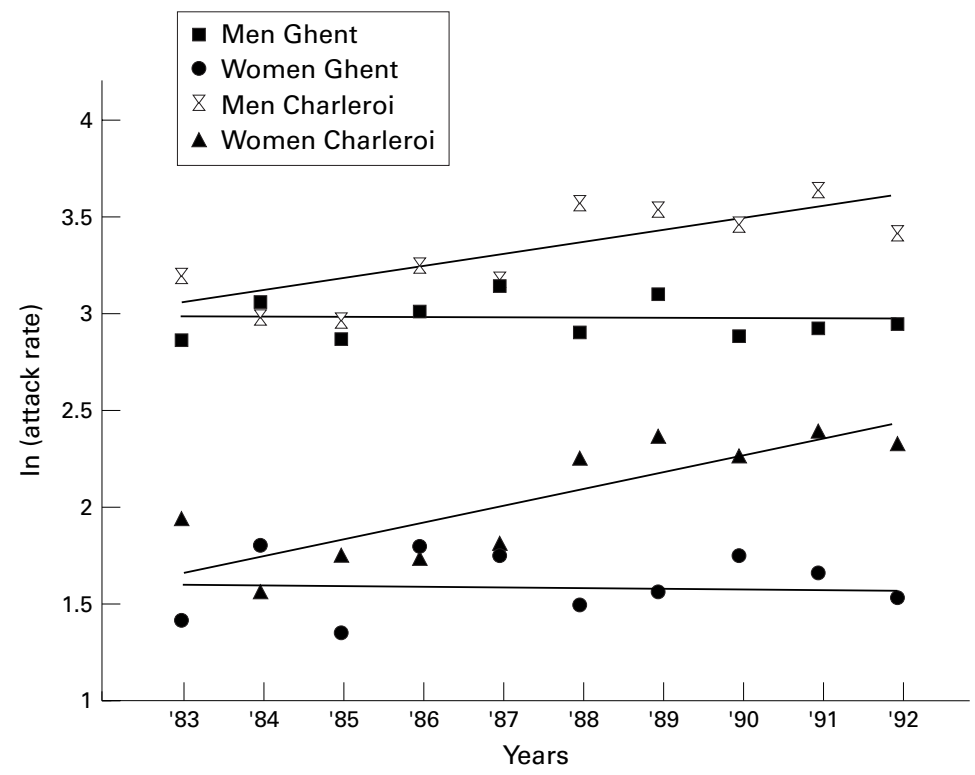

Figure 2 Trends in attack rates of non-fatal acute coronary events over a 10 year period (1983-1992) by reporting unit and by sex.

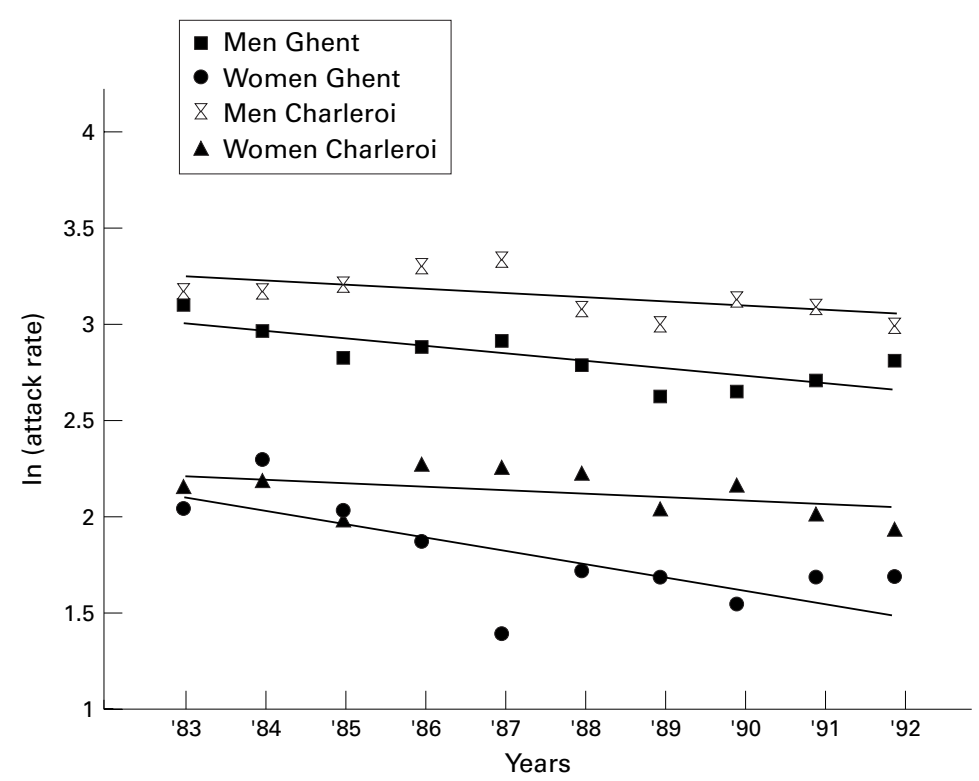

Figure 3 Trends in attack rates of fatal acute coronary events over a 10 year period (1983-1992) by reporting unit and by sex.

Events are called "fatal" if death follows within 28 days from the onset of acute symptoms. The same time frame differentiates first from recurrent acute coronary events.

Events are called "definite" if they present with at least either a diagnostic progression of Minnesota codes on serial ECGs and/or with serum cardiac enzymes at least twice the limit of normal and/or-for fatal events onlycoronary artery findings of acute coronary occlusion at necropsy.

"Possible" events must have presented with suggestive symptoms (typical chest pain for at least 20 minutes) but with lesser or no ECG and enzyme findings, in the absence of any other diagnosis for the attack; in fatal cases, a documented history of CHD and/or necropsy findings of chronic occlusive CHD or old infarction also qualify for the label "possible AMI".

The category "ischaemic cardiac arrest" contains (rare) non-fatal cases, in whom ischaemic cardiac arrest has been reversed and that are not fulfilling criteria for "definite" or "possible AMI".

"Fatal events with insufficient data" are fatal cases, for which no necropsy data and no data on symptoms nor on personal history of CHD are available and for which no other (than CHD) cause of death could be demonstrated.

Patients in the "no AMI" category had either very aspecific symptoms or symptoms definitively based on a non-CHD pathology.

In this paper, the term "attack rate" refers to incidence rate of events, irrespective of the medical antecedents - that is, not taking into account whether it was a first or a recurrent acute coronary event. The term "incidence rate" is used solely for the occurrence of "first" events.

However, in a substantial proportion of cases (alltogether $18.2 \%$ in Ghent and $19.4 \%$ in Charleroi) the information on medical antecedents was missing; hence it cannot be pursued whether these cases were first or recurrent events. In the results section, data on incidence rates are therefore calculated according to two scenarios, one assuming that all missing cases were first events and a second assuming that all missing cases were recurrent events. As the "true" incidence rates necessarily fall within the borders of these two extremes, interpretation of trends can in many cases yet be done with acceptable precision.

\section{STATISTICS}

Event rates were age standardised using Belgian population data (age range 25-69 years) of 1 January 1988 as a reference. Trends in attack rates and incidence rates were studied in the framework of Poisson regression modelling. In its simplest linear form this Poisson model is defined:

$$
\operatorname{Ln}(\text { event rate })=\beta_{0}+\beta_{1} \times \text { time }+\varepsilon
$$

where $\operatorname{Ln}$ is the natural logarithm, $\beta_{0}$ and $\beta_{1}$ are regression coefficients to be estimated, and $\varepsilon$ is the error term that is assumed to follow a Poisson distribution. The model regression parameters were estimated using the maximum likelihood procedure. To study a possible violation of the linearity assumption, a quadratic term was introduced in each model as a first step and was tested on its significance. In none of the models was the quadratic effect of time proved to be of statistical significance. The model fit was further evaluated by graphical display of the Pearson residuals, which turned out to fluctuate randomly around zero. Studying these residuals into more detail revealed some outlying observations such as the year 1987 for fatal attack data in women from Ghent (see fig 3), but no systematic pattern was found that would suggest a deviation from linearity in a certain time period. The estimated rate ratios associated with a time period of 10 years $(t=10$ 
Table 3 Trends in incidence rates (/10 000) for all events, non-fatal events, and fatal events in Ghent according to two different scenarios

\begin{tabular}{|c|c|c|c|c|c|c|c|c|c|c|c|c|}
\hline & \multicolumn{6}{|l|}{ Men } & \multicolumn{6}{|l|}{ Women } \\
\hline & \multicolumn{2}{|l|}{$N F+F$} & \multicolumn{2}{|c|}{ Non-fatal } & \multicolumn{2}{|l|}{ Fatal } & \multicolumn{2}{|l|}{$N F+F$} & \multicolumn{2}{|c|}{ Non-fatal } & \multicolumn{2}{|l|}{ Fatal } \\
\hline & scen 1 & scen 2 & scen 1 & scen 2 & scen 1 & scen 2 & scen 1 & scen 2 & scen 1 & scen 2 & scen 1 & scen 2 \\
\hline 1983 & 24.1 & 30.0 & 12.0 & 13.4 & 12.2 & 16.6 & 7.8 & 9.4 & 2.8 & 2.8 & 4.9 & 6.6 \\
\hline 1984 & 28.9 & 33.0 & 16.6 & 16.6 & 12.3 & 16.4 & 11.7 & 13.0 & 4.5 & 4.5 & 7.2 & 8.5 \\
\hline 1985 & 21.5 & 26.9 & 13.7 & 14.2 & 7.8 & 12.7 & 6.3 & 8.7 & 3.2 & 3.2 & 3.1 & 5.4 \\
\hline 1986 & 24.9 & 29.2 & 16.0 & 16.5 & 8.9 & 12.7 & 7.9 & 9.8 & 4.3 & 4.7 & 3.6 & 5.1 \\
\hline 1987 & 28.9 & 34.0 & 19.4 & 19.7 & 9.5 & 14.3 & 6.9 & 7.2 & 4.7 & 4.7 & 2.2 & 2.5 \\
\hline 1988 & 21.0 & 28.7 & 15.5 & 15.7 & 5.5 & 13.0 & 6.4 & 8.9 & 3.6 & 3.7 & 2.8 & 5.2 \\
\hline 1989 & 21.3 & 30.0 & 18.1 & 18.2 & 3.3 & 11.8 & 6.3 & 9.1 & 3.6 & 3.9 & 2.6 & 5.2 \\
\hline 1990 & 19.9 & 25.9 & 14.1 & 14.3 & 5.8 & 11.7 & 6.7 & 8.9 & 4.6 & 4.8 & 2.1 & 4.1 \\
\hline 1991 & 18.2 & 26.6 & 13.7 & 13.8 & 4.5 & 12.8 & 6.0 & 9.3 & 4.2 & 4.2 & 1.8 & 5.0 \\
\hline 1992 & 19.7 & 28.6 & 15.2 & 15.4 & 4.5 & 13.3 & 5.4 & 8.7 & 3.9 & 3.9 & 1.4 & 4.7 \\
\hline Trend ${ }^{\star}$ & - & - & + & - & - & - & - & - & + & + & - & - \\
\hline $\mathrm{p}$ Valuet & $<0.001$ & 0.086 & 0.66 & 0.96 & $<0.001$ & 0.015 & $<0.001$ & 0.14 & 0.40 & 0.37 & $<0.001$ & 0.005 \\
\hline
\end{tabular}

scen: scenario, NF: non-fatal, F: fatal. Scenario 1: assuming that all cases with missing information were first events. Scenario 2: assuming that all cases with missing information were recurrent events. ${ }^{\star}$ Trends are indicated as negative if the Poisson regression line had a negative slope and as positive if this regression line had a positive slope. tp Value for the test of slope deviating from zero in the Poisson regression analysis.

versus $\mathrm{t}=0$ ) according to the fitted model and expressed as the per cent change in event rates over this 10 year time period were calculated by exponentiation of the estimated regression parameters according to the following algorithm:

$$
\begin{aligned}
& \ln \left(\text { event } \text { rate }_{\mathrm{t}=0}\right)=\mathrm{a}+\mathrm{b} \times 0 \\
& \ln \left(\text { event } \text { rate }_{t=10}\right)=a+b \times 10 \\
& \ln \left(\text { event } \text { rate }_{\mathrm{t}=10} / \text { event rate }_{\mathrm{t}=0}\right)=\mathrm{b} \times 10 \\
& \text { rate } \operatorname{ratio}(\mathrm{t}=10 / \mathrm{t}=0)=\mathrm{e}^{\mathrm{b} \times 10} \\
& =(\text { rate ratio }-1) \times 100
\end{aligned}
$$$$
\ln \left(\text { event } \text { rate }_{t=10}\right)-\ln (\text { event rate } \text { re=0 })=\mathrm{b} \times 10
$$

The corresponding 95\% confidence limits were calculated as follows:

$95 \%$ CI of the rate ratio $=\mathrm{e}^{[\mathrm{bt1.96 \times SE}(b)] \times 10}$

$95 \% \mathrm{CI}=[(95 \% \mathrm{CI}$ of the rate ratio $)-1] \times 100$

Trends in case fatality rates were studied in an analogous way as trends in event rates, now using logistic regression models. Here also, the quadratic effect of time was statistically not significant in any of the models and therefore linear models were fitted. Rate ratios over a 10 year time period and corresponding $95 \%$ confidence limits were calculated in an analogous way as for event rates.

All statistical analyses were performed using SAS software. A significance level of $\alpha=0.05$ was adopted to indicate statistical significance.

\section{Results}

Table 1 shows-for the total 10 year registration period-the distribution of acute coronary events across the different diagnostic categories that are used in MONICA for nonfatal and fatal events by reporting unit and by sex. In Ghent, a total number of 2443 acute coronary events were registered in men and 788 in women. In Charleroi these figures were 3136 for men and 1064 for women.

The distribution of acute coronary events over the different categories did not significantly change over the 10 year time period (data not shown). In all subgroups as defined by sex and centre, a large majority of non-fatal

\begin{tabular}{|c|c|c|c|c|c|c|c|c|c|c|c|c|}
\hline & \multicolumn{6}{|l|}{ Men } & \multicolumn{6}{|l|}{ Women } \\
\hline & \multicolumn{2}{|l|}{$N F+F$} & \multicolumn{2}{|c|}{ Non-fatal } & \multicolumn{2}{|l|}{ Fatal } & \multicolumn{2}{|l|}{$N F+F$} & \multicolumn{2}{|c|}{ Non-fatal } & \multicolumn{2}{|l|}{ Fatal } \\
\hline & scen 1 & scen 2 & scen 1 & scen 2 & scen 1 & scen 2 & scen 1 & scen 2 & scen 1 & scen 2 & scen 1 & $\operatorname{scen} 2$ \\
\hline 1983 & 30.4 & 34.8 & 18.2 & 18.9 & 12.1 & 15.9 & 10.0 & 12.0 & 5.4 & 5.5 & 4.6 & 6.6 \\
\hline 1984 & 22.5 & 32.7 & 15.8 & 16.2 & 6.7 & 16.6 & 9.1 & 11.9 & 4.2 & 4.2 & 4.9 & 7.8 \\
\hline 1985 & 21.8 & 33.5 & 14.1 & 14.8 & 7.6 & 18.7 & 7.1 & 10.3 & 4.3 & 4.7 & 2.8 & 5.6 \\
\hline 1986 & 27.7 & 38.8 & 20.2 & 20.6 & 7.5 & 18.3 & 7.1 & 12.0 & 4.0 & 4.7 & 3.1 & 7.3 \\
\hline 1987 & 28.3 & 41.9 & 19.4 & 19.9 & 8.9 & 22.0 & 10.4 & 13.3 & 5.1 & 5.1 & 5.3 & 8.3 \\
\hline 1988 & 36.9 & 46.0 & 25.8 & 27.8 & 11.1 & 18.3 & 11.8 & 15.8 & 7.1 & 7.9 & 4.6 & 7.8 \\
\hline 1989 & 33.1 & 40.8 & 25.6 & 25.9 & 7.5 & 14.9 & 12.5 & 15.7 & 9.0 & 9.0 & 3.5 & 6.7 \\
\hline 1990 & 29.4 & 42.3 & 24.7 & 24.8 & 4.7 & 17.5 & 10.2 & 16.2 & 7.8 & 7.9 & 2.4 & 8.2 \\
\hline 1991 & 35.9 & 43.4 & 27.9 & 27.9 & 8.0 & 15.5 & 11.7 & 14.6 & 8.4 & 8.6 & 3.2 & 6.0 \\
\hline 1992 & 31.4 & 40.0 & 22.8 & 23.0 & 8.5 & 17.0 & 10.4 & 14.2 & 8.1 & 8.1 & 2.3 & 6.1 \\
\hline Trend $\star$ & + & + & + & + & - & - & + & + & + & + & - & - \\
\hline $\mathrm{p}$ Valuet & $<0.001$ & $<0.001$ & $<0.001$ & $<0.001$ & 0.09 & 0.57 & 0.020 & 0.003 & $<0.001$ & $<0.001$ & 0.015 & 0.75 \\
\hline
\end{tabular}
cases were classified as "definite" (varying from $69.7 \%$ in women from Charleroi to $81.7 \%$ in men from Ghent).

Table 4 Trends in incidence rates (110 000) for all events, non-fatal events, and fatal events in Charleroi according to two different scenarios

scen: scenario, NF: non-fatal, F: fatal. Scenario 1: assuming that all cases with missing information were first events. Scenario 2: assuming that all cases with missing information were recurrent events. ${ }^{\star}$ Trends are indicated as negative if the Poisson regression line had a negative slope ans as positive if this regression line had a positive slope. tp Value for the test of slope deviating from zero in the Poisson regression analysis. 


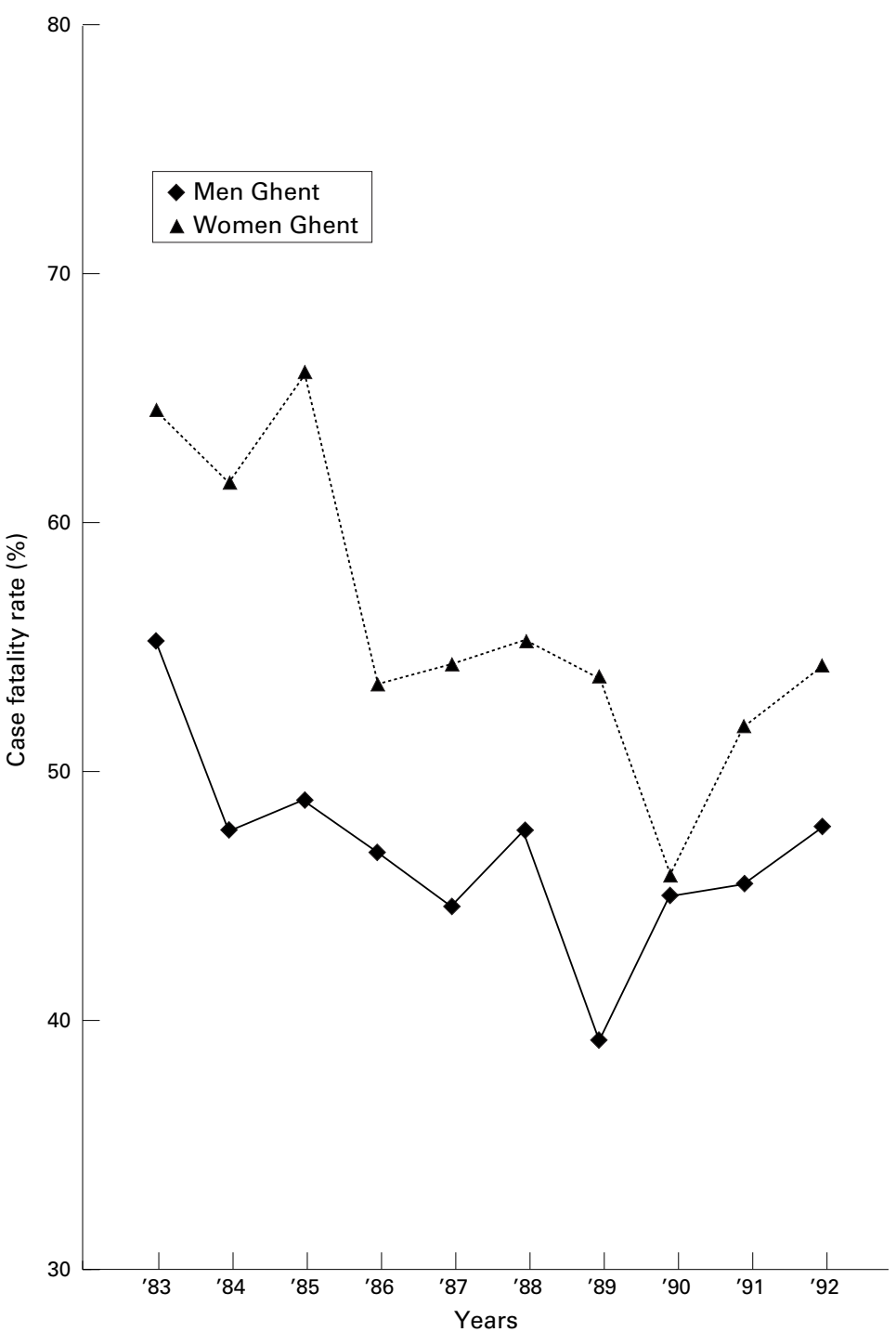

Figure 4 Trends in overall case fatality rate of acute coronary events over a 10 year period (1983-1992) in Ghent by sex. non-fatal, and 2.7 for fatal attack rates. In Charleroi, it was respectively 3.1, 3.4, and 2.7.

Figures 1, 2, and 3 give a graphical presentation of the Poisson regression analyses of trends over the 10 year registration period, respectively for total, non-fatal, and fatal attack rates, by reporting unit and by sex. These figures show fitted regression lines with scatter points corresponding to the yearly attack rates.

For total attack rates (fig 1), diverging trends are observed between Ghent and Charleroi. In Ghent, a significant decrease $(p<0.01)$ was observed in both sexes. The per cent change over 10 years was $-18 \%(95 \% \mathrm{CI}-29 \%$ to $-5 \%)$ in men and $-30 \%(95 \% \mathrm{CI}-45 \%$ to $-10 \%)$ in women. In Charleroi, a significant increase $(p<0.01)$ was found in both sexes. The proportional increase over 10 years was $+25 \%$ $(95 \% \mathrm{CI}+10 \%$ to $+41 \%)$ in men and $+36 \%$ $(95 \% \mathrm{CI}+10 \%$ to $69 \%)$ in women.

In Ghent, attack rates of non-fatal events showed no significant changes over the 10 year registration period in both sexes (fig 2). In Charleroi, a significant increase was found in both men and women $(\mathrm{p}<0.001)$. The proportional change over the 10 years in Charleroi was $+82 \%(95 \% \mathrm{CI}+54 \%$ to $+116 \%)$ in men and $+132 \%(95 \% \mathrm{CI}+69 \%$ to $+218 \%)$ in women.

For attack rates of fatal events (fig 3), significant decreases were found in Ghent in both sexes $(p<0.01$ for men and $p<0.001$ for women) and in men in Charleroi $(p<0.01)$. Proportional changes over 10 years were in Ghent $-33 \%$ (95\% CI $-45 \%$ to $-17 \%)$ in men and $-50 \% \quad(95 \% \mathrm{CI}-64 \%$ to $-30 \%)$ in women. In Charleroi, $-20 \%$ (95\% CI $-34 \%$ to $-4 \%)$ in men and $-17 \%(95 \% \mathrm{CI}-39 \%$ to $+12 \%$ ) in women.

As explained in the Methods section, no exact rates can be given for incidence rates ("first" events) as the information on medical antecedents was missing in a substantial proportion of cases (18.2\% in Ghent and $19.4 \%$ in Charleroi). Therefore, event rates are given in table 3 (for Ghent) and table 4 (for Charleroi) according to two approximative scenarios, scenario 1 assuming that all cases with missing information were first events and scenario 2 assuming that all these cases were recurrent cases. The "real" trends in event rates necessarily fall between these two extremes. For both scenarios, trends were studied using Poisson regression analysis ( $\mathrm{p}$ values in tables 3 and 4 ).

The results in table 3 allow us to conclude that total incidence rates in Ghent follow a trend that falls somewhere between a highly significant decrease and a borderline significant decrease, in both sexes strongly suggestive for a true decrease. In both men and women, incidence rates of non-fatal events show a steady state evolution over the years of registration (trends according to Poisson regression analyses are non-significant in the two scenarios for both sexes). Incidence rates of fatal events definitely show a significant decline in both sexes.

The results in table 4 allow us to conclude that both the total incidence rates and the incidence rates of non-fatal events are definitely 


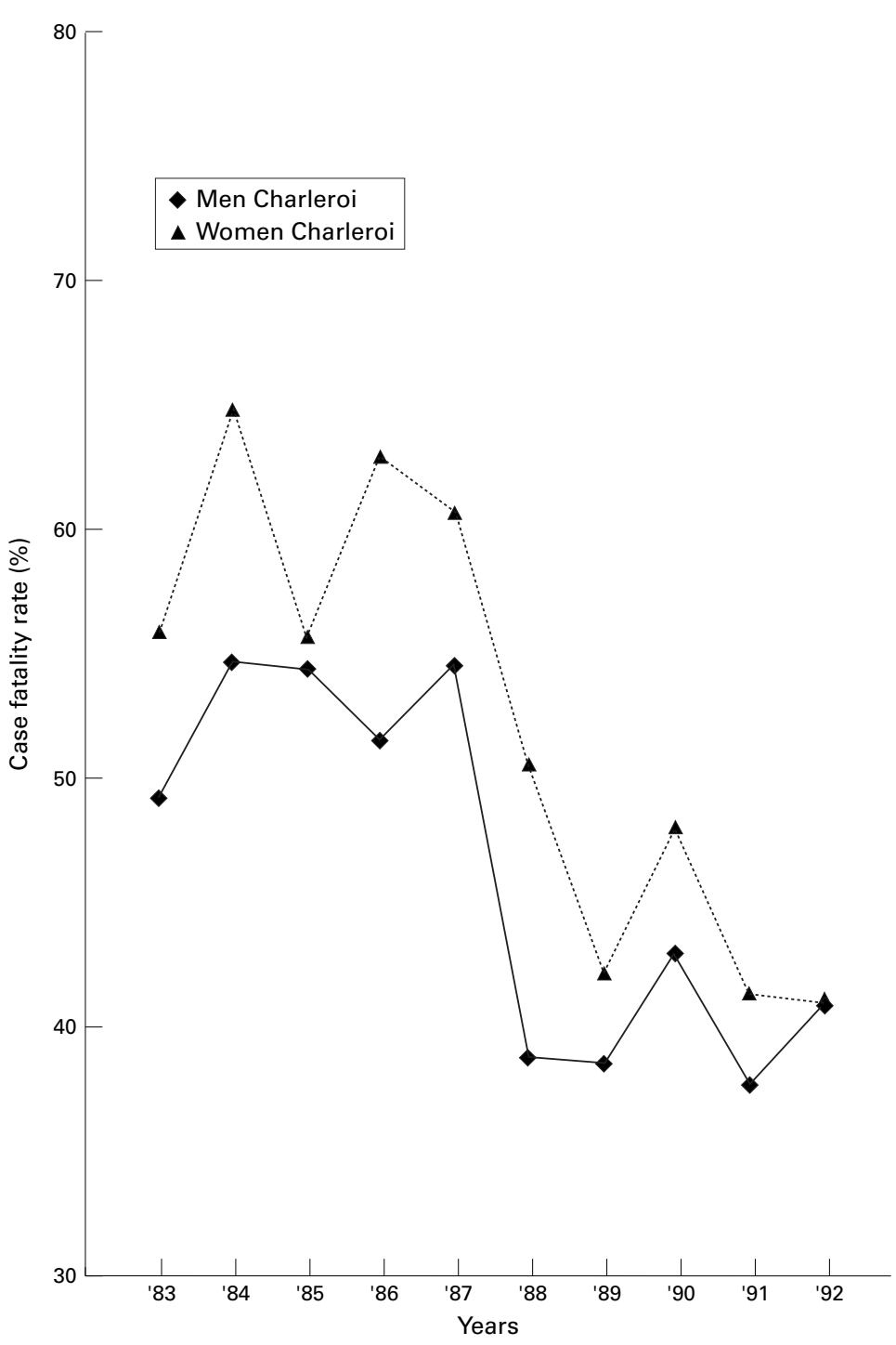

Figure 5 Trends in overall case fatality rate of acute coronary events over a 10 year period (1983-1992) in Charleroi by sex.

increasing significantly in the two sexes in Charleroi ( $p$ values less than 0.05 in the two scenarios for both men and women). Although trends in incidence rates of fatal events in Charleroi are negative in the two scenarios in both sexes, the overall picture is not convincingly suggestive for a true decline and statistical significance is reached only in women in scenario 1.

On the whole, the results for incidence rates parallel very well the results for attack rates, except for trends in fatal events in Charleroi.

Figures 4 and 5 show trends in the overall case fatality rate over the 10 year registration period for men and women in Ghent and Charleroi respectively. In both Ghent and Charleroi, a significant $(\mathrm{p}<0.05)$ decrease in overall case fatality was observed in men and in women. The proportional decline over the 10 year period was $-27 \%(95 \% \mathrm{CI}-45 \%$ to $-3 \%)$ in men and $-47 \%(95 \% \mathrm{CI}-67 \%$ to $-14 \%)$ in women in Ghent. In Charleroi, the 10 year decline was $-53 \%(95 \% \mathrm{CI}-64 \%$ to $-40 \%)$ in men and $-64 \%(95 \% \mathrm{CI}-77 \%$ to $-44 \%)$ in women.

Figures 6 and 7 show in hospital case fatality trends over the 10 year register period for the two sexes and the two centres respectively. Again, significant decreases in in hospital case fatality were observed in men and in women in the two reporting units. The decrease over 10 years was $-56 \%(95 \% \mathrm{CI}-70 \%$ to $-33 \%)$ in men and $-52 \%(95 \% \mathrm{CI}-75 \%$ to $-7 \%)$ in women in Ghent. The decreases in Charleroi were $-57 \%(95 \% \mathrm{CI}-69 \%$ to $-38 \%)$ in men and $-62 \%(95 \% \mathrm{CI}-78 \%$ to $-33 \%)$ in women.

\section{Discussion}

According to the official vital statistics, the CHD mortality in Belgium has shown diverging trends since 1950. Like in many industrialised countries, an epidemic rise in CHD mortality has taken place in both sexes after the second world war, reaching its maximum and turning point in the late sixties. ${ }^{4}$ Since then, a gradual decrease has been observed. Between 1968 and 1977, Belgian men showed the most pronounced decrease in CHD mortality within Europe $(-1.7 \%$ per year $)$, together with Finnish men. ${ }^{1}$ This decline in official CHD mortality is continuing until today and is accompanied by similar patterns in total mortality. According to the latest available WHO figures (1989), Belgium is now among the (mostly Mediterranean) countries with the lowest official CHD mortality in Europe with age standardised figures comparable to those in Greece, lower than in Italy, but higher than in Spain and France. ${ }^{27}$

Trends in mortality statistics are widely used for public health purposes. However, it is not very clear to what extent mortality statistics as only source of information allow us to accurately study the true trends in the occurrence of CHD. The quality of vital statistics is known to vary considerably over time and between countries ${ }^{16-19}$ and according to Stehbens,${ }^{18}$ mortality statistics can in no way be used for any scientific purpose. Specifically for Belgium, the vital statistics have been shown to underestimate substantially the true mortality of CHD. ${ }^{26}{ }^{28}$ Furthermore, mortality statistics provide only a fragmentary picture of the real occurrence of CHD as the non-fatal form of the disease is not taken into account. Hence, changes in CHD mortality can be misleading as they can be the resultant of differing underlying processes, in which incidence rates for fatal and non-fatal CHD and case fatality rates of the disease can go in either parallel or diverging directions. The results in this paper illustrate this and also show how the overall official mortality statistics for Belgium are masking important regional differences in the occurrence and in trends of CHD within the country. Similar findings have been reported for several other countries. ${ }^{29} 30$

A first important observation in this paper is that the incidence of CHD is on average $50 \%$ higher in Charleroi compared with Ghent. The average event rate ratio Charleroi/Ghent was 1.5 in both sexes over the period 1983-1992. Secondly, trends over time show important dif- 


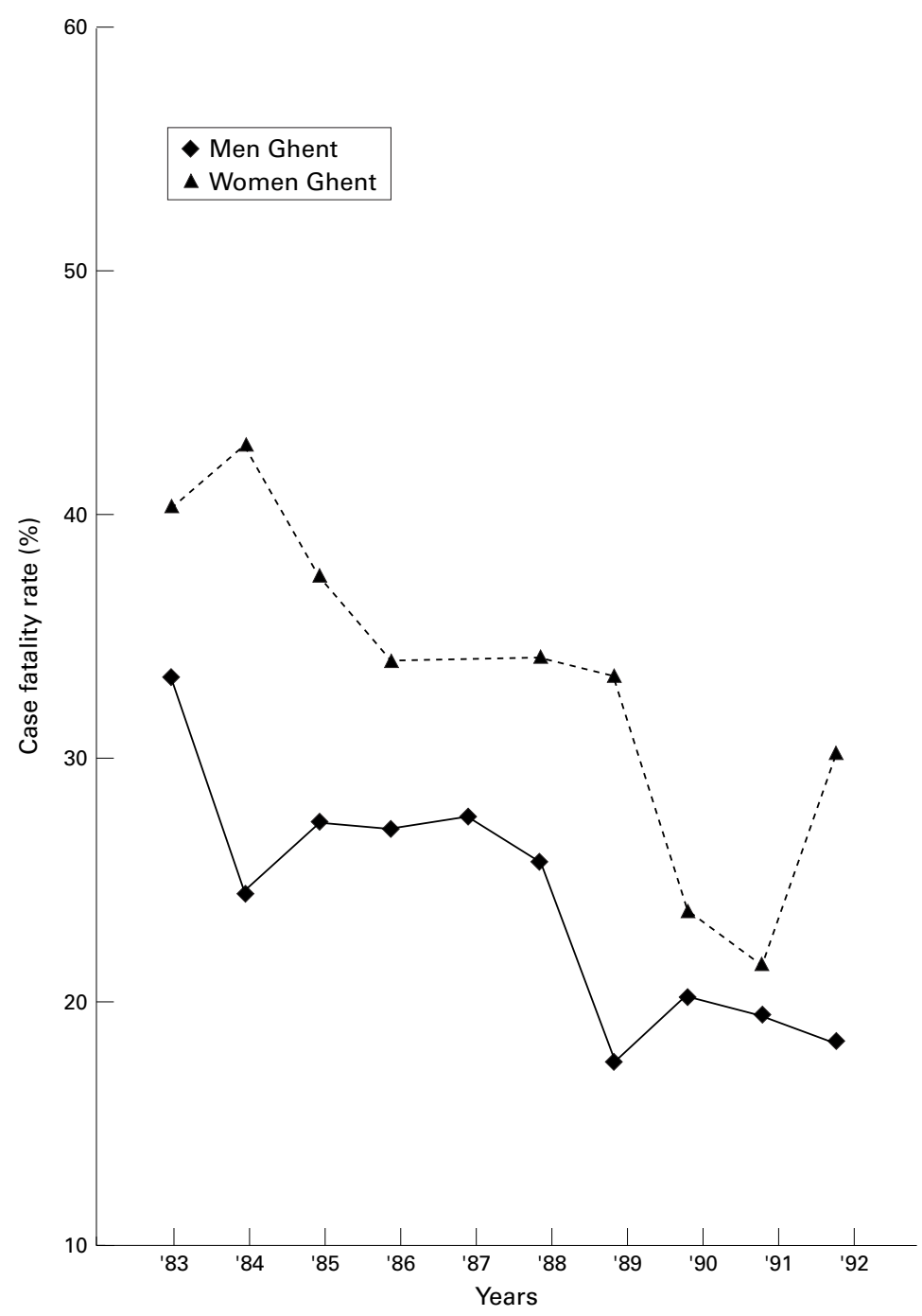

Figure 6 Trends in "in hospital" case fatality rate of acute coronary events over a 10 year period (1983-1992) in Ghent by sex. ferences between the two reporting units Ghent and Charleroi. In Ghent, total attack rates of acute coronary events have decreased over the 10 year registration period at a rate of on average $-1.8 \%$ per year in men and $-3.0 \%$ per year in women. This seems to be entirely accounted for by a decrease in fatal events $(-3.3 \%$ per year in men and $-5.0 \%$ per year in women), while attack rates of non-fatal events did not change. The diverging trend between non-fatal and fatal event rates is compatible with a significant decline in the lethality of acute coronary events in Ghent (fig 4).

In contrast with these overall favourable findings in Ghent, trends in event rates in Charleroi show an unfavourable evolution. Total attack rates in Charleroi have increased over the 10 year registration period at an average annual rate of $+2.5 \%$ in men and $+3.6 \%$ in women. Non-fatal event rates are increasing more rapidly $(+8.2 \%$ per year in men and $+13.2 \%$ per year in women), while changes in fatal event rates are rather uncertain and inconsistent (a statistically significant decrease only for attack rates of fatal events in men, while incidence rates of fatal events are not convincingly suggestive for a significant downward trend in both sexes). A positive finding in Charleroi was the significant decline in case fatality of the disease.

The two constituting regions of BelgiumFlanders and Wallonia-are in terms of cultural identity (inclusively the language), substantially different entities and this warrants a separate treatment of morbidity and mortality data in public health context. Obviously, it is very difficult to assess to what extent our register areas are representative for the communities they are located in, as subregional differences and differences between urban and rural areas can be expected to exist within each community. However, it strongly looks as if the differences in total CHD incidence observed in this study are a reflection of the known differences in overall coronary risk factor burden between the north and the south of Belgium, as has been demonstrated by several epidemiological studies carried out in Belgium over the past 25 years. ${ }^{20-24}$ These cross sectional risk factor surveys have consistently indicated that Flanders and Wallonia each show more or less homogeneous within community coronary risk factor profiles, while the overall burden of coronary risk factors on population level is substantially higher in Wallonia. The most important known significant differences are the higher mean serum total cholesterol values, the higher intake of saturated fatty acids, and the lower intake of polyunsaturated fatty acids in Wallonia compared with Flanders. ${ }^{20-24}$ Data from two cross sectional coronary risk factor surveys carried out in the same standardised way in Ghent and Charleroi between 1985 and 1990, revealed that both men and women from Charleroi have statistically significant higher mean systolic and diastolic blood pressure values, higher mean serum total cholesterol values, higher mean BMI values, and a higher mean total and saturated fat intake than people from Ghent, while for smoking no differences were found (data not shown; unpublished data).

The diverging trends in CHD incidence between Ghent and Charleroi further suggest that the gap between the two regions in terms of overall CHD burden has still been broadening during the decade of the eighties. The event rate ratio Charleroi/Ghent was in 19831.2 in men and 1.3 in women, while it was respectively 1.4 and 1.7 in 1992. Altogether, these epidemiological data strongly suggest the existence of important regional differences in acute coronary disease in Belgium and hence the need for differential emphases in the preventive strategies in the two communities. Furthermore, the existence of these important differences points towards the continued need for further monitoring of both cardiovascular risk factors and coronary artery disease occurrence in the two Belgian regions.

Interestingly, as a result of the complex political situation in Belgium, the organisation and financing of health services is a federal responsability, while a number of determinants of 


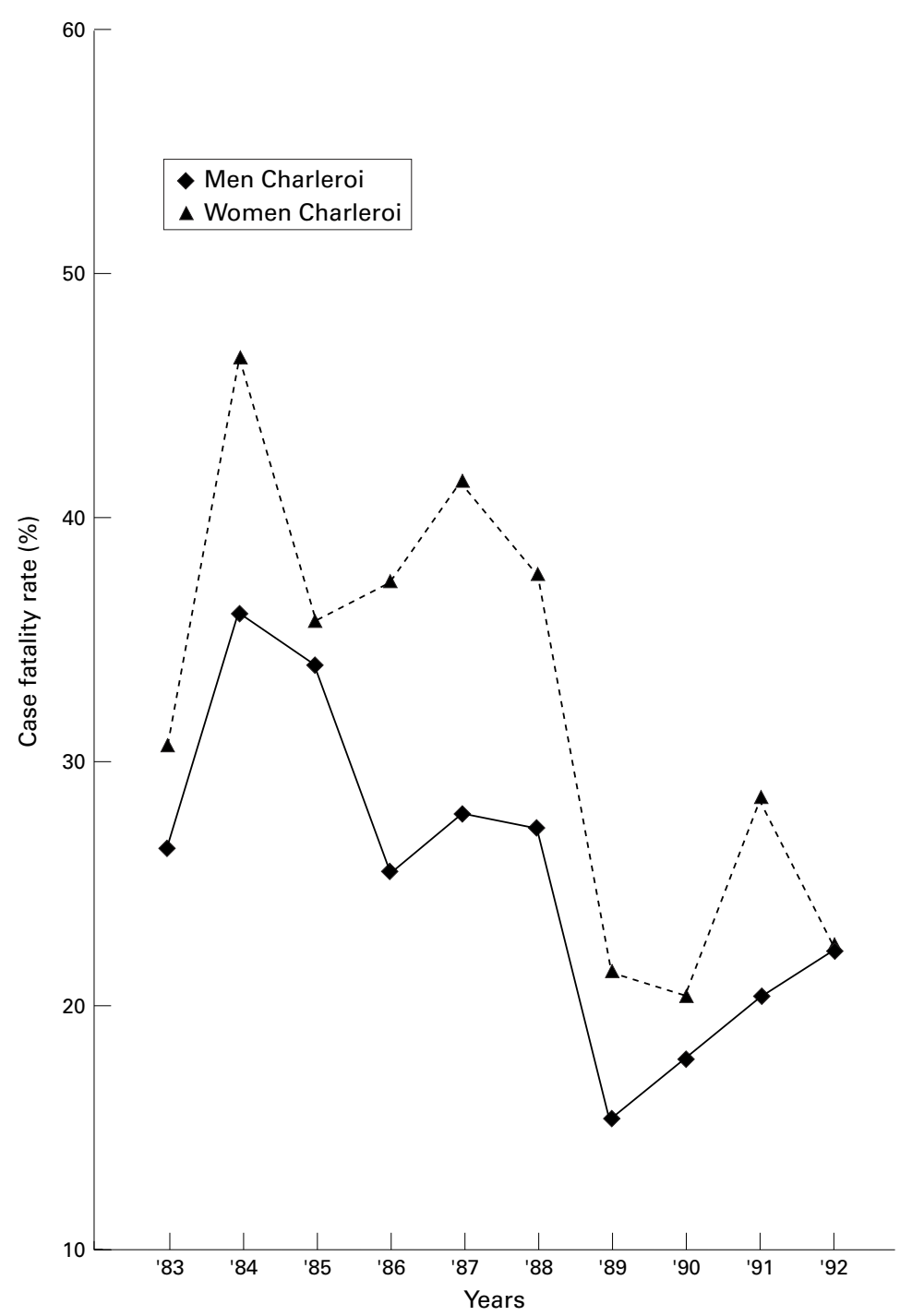

Figure 7 Trends in "in hospital" case fatality rate of acute coronary events over a 10 year period (1983-1992) in Charleroi by sex.

economic growth are partly subject to initiatives and funding from the regional governments.

Theoretically, the availability of and the personal financial threshold for the use of health services is the same in the two communities. However, over the past few decades, a number of indicators of the socioeconomic climate, for example, unemployment rates, have been showing diverging trends in the two communities, the overall economic situation being substantially more favourable in Flanders. Moreover, the diverging trends in socioeconomic situation in the two cities Ghent and Charleroi parallel remarkably well the diverging trends in CHD incidence in these two cities ( $M$ Kornitzer, personal communication). In analogy with the work of Marmot, convincingly showing that social and economic forces in societies are important determinants of trends in CHD, ${ }^{31}$ it can be hypothesised that the less favourable overall socioeconomic situation in the south of the country (Wallonia) could play a part in a possible process of lower overall preventive impact exerted by physi- cians and a lower therapeutic compliance in the treatment of coronary risk factors.

In sharp contrast with the large differences between Ghent and Charleroi in the incidence rates of $\mathrm{CHD}$, the overall and in hospital case fatality rates show only small differences between the two reporting units. The case fatality rate ratio Charleroi/Ghent was 0.97 in men and 0.92 in women for total case fatality rate and 1.02 in men and 0.96 in women for "in hospital" case fatality rate. Likewise, a remarkable parallel was observed in trends in case fatality rate in the two reporting units. Overall case fatality of CHD is significantly declining in both regions and in both sexes from $64.6 \%$ in women in Ghent in 1983 to $40.7 \%$ in women in Charleroi in 1992. In hospital case fatality rate declined significantly from $40.4 \%$ in women in Ghent in 1983 to $18.1 \%$ in men in Ghent in 1992. The fact that case fatality rate is practically the same in the two centres suggests that the severity of the disease and the efficiency of treatment is similar in the two cities, although this cannot with certainty be derived from our data. The parallelism in the trends in case fatality rates further suggests that the introduction during the eighties - in Belgium like in many other Western countries - of important new diagnostic and therapeutic procedures in clinical medicine (including new drugs like aspirin and thrombolytic agents as well as revascularisation procedures) has been realised in the two areas in the same way at the same time and has not been subject to socioeconomic differences between Flanders and Wallonia; the federal governmental financial input in clinical medicine is indeed, and has always been, proportionally divided over the two communities.

It is clear, however, that changes in the natural history of the disease can also have played a part in this evolution in case fatality rates. Anyway, a decline in "in hospital" case fatality of AMI has been reported recently for several other countries. ${ }^{32-34}$

It must be noted, however, that the total and "in hospital" case fatality of CHD is in absolute terms still very high. The "in hospital" case fatality observed in this study is in any case substantially higher than what has been suggested by recent clinical trials on treatment of AMI like the Gissi, ${ }^{35}$ the Gusto, ${ }^{36}$ and the ISIS IV trial. ${ }^{37}$ The lower "in hospital" case fatality rate in these trials is probably because of a selection of patients, who have to meet specific trial protocol criteria and are therefore, in contrast with the study population in this paper, not representative for the total population of hospitalised AMI patients. The study of the determinants of AMI lethality should be a major public health target to find ways to reduce further the overall burden of the disease.

A "de visu" inspection of figures 1 to 7 could suggest a non-linearity of the trends in event rates and in case fatality rates. Especially for total and non-fatal event rates in women (figures 1-2), the existence of a "change-point" could be assumed in the years 1987-8 while the trends in case fatality seem to show a transition ("knee-effect") of a decreasing trend towards a 
status quo evolution in 1988-9 in both sexes in the two centres. However, fitting quadratic models for both event rates and case fatality rates revealed no single statistically significant quadratic effect of time, indicating that a simple linear fit to the data is appropriate (see Statistics). It could well be hypothesised that for case fatality a change in the evolution has taken place since 1988-9, which will perhaps only be detected when more points of observation after 1992 are available.

The MONICA category of non-fatal "possible" cases contains events with sustained $(>20$ minutes) typical chest pain for whom ECG signs and cardiac enzymes concentrations were not sufficiently convincing to categorise them as "definite AMI". Undoubtedly, this category could, although it constitutes a minority of cases, have some negative influence on the specificity of the MONICA AMI register as it could also contain some cases of angina pectoris. This category was however still included in the analyses for two main reasons. Firstly, sample size calculation at the beginning of the study had indicated that the population denominators in Ghent and Charleroi were only borderline to generate sufficient cases to detect time trends, if present. Hence, any loss of cases was to be avoided as much as possible. Secondly, trend analyses showed that the proportion of non-fatal "possible" cases within the total group of non-fatal cases remained stable over time (data not shown) in both Ghent and Charleroi and therefore has had no influence on time trends, the main topic of this paper.

In contrast, the proportion of non-fatal "possible" cases within the total group of nonfatal cases was - consistently over the 10 year period-higher in Charleroi compared with Ghent (data not shown) and this could possibly point towards small systematic differences in the case ascertainment procedures between the two centres. If so, this could have had an artefactual influence on the between centre comparisons. However, the differences in these proportions between Ghent and Charleroi are rather small (mean difference $6.4 \%$ in men and $4.3 \%$ in women) and moreover this category of non-fatal possible cases represents a small proportion of the total number of cases (see table 1). It is therefore concluded that the impact of this potential "measurement error" on the main conclusions of this paper is negligable.

The relatively large proportion of "fatal events with insufficient data" might at first sight suggest a low overall specificity of the Belgian MONICA register for fatal events. However, the majority of cases in this category (78.4\% in Ghent and $72.3 \%$ in Charleroi) are cases of sudden (cardiac) death, for which no apparent non-cardiac or cardiac non-ischaemic cause of death could be diagnosed. In Belgium, almost no necropsy data are available for such cases. There are, however, no arguments to assume that the underlying causes of sudden cardiac deaths would in Belgium be different from those found in large necropsy studies, ${ }^{38}$ showing that acute coronary incidents are indeed the causative factor in a large majority of these deaths. Again, time trend analysis has shown that the proportion of "fatal events with insufficient data" within the total group of fatal cases has remained stable over time in the two reporting units (data not shown). It is therefore concluded that no changes in case ascertainment procedures for fatal events have taken place and hence that inclusion of this category has had no influence on time trends.

In conclusion, important differences in CHD incidence and CHD trends were observed between two cities, Ghent and Charleroi, situated in the two different constituting communities of Belgium. These findings parallel well the known socioeconomic differences between Ghent in the north (Flanders) and Charleroi in the south (Wallonia) of Belgium. No differences were observed in case fatality rates. It can be speculated that the observed differences in these two cities are representative for the north/south proportions in CHD occurrence in Belgium as important and still growing differences in overall socioeconomic situation between the two regions are well documented and are strongly in favour of Flanders. These findings warrant more systematic research in this field in larger and more representative areas for the two communities Flanders and Wallonia.

The authors would like to thank all medical doctors and other key persons that have collaborated in the MONICA project in the two areas Ghent and Charleroi.

Funding: this work was funded by grant no 33.9002 .84 of the Belgian National Research Fund.

1 Pisa Z, Uemura K. Trends in mortality from ischemic heart disease and other cardiovascular diseases in 27 countries, 1968-1977. World Health Stat Q 1982;35:11-47.

2 Salonen JT, Puska P, Kottke TE, et al. Decline in mortality from coronary heart disease in Finland from 1969 to 1979. BMF 1983;286:1857-60.

3 Uemura K, Pisa Z. Recent trends in cardiovascular disease mortality in 27 industrialised countries. World Health Stat $Q$ 1985;38:142-62.

4 Uemura K, Pisa Z. Trends in cardiovascular disease mortality in industrialised countries since 1950. World Health Stat lity in industrialised co

5 Thom TJ. International mortality from heart disease: rates and trends. Int $\mathcal{F}$ Epidemiol 1989;18 (suppl 1):S20-8.

and trends. Int $\mathcal{F}$ Epidemiol 1989;18 (suppl 1):S20-8.
6 Menotti A. Trends in CHD in Italy. Int f Epidemiol 1989;18 (suppl 1):S125-8.

7 Hatano S. Changing CHD mortality and its causes in Japan during 1955-1985. Int $\mathcal{f}$ Epidemiol 1989;18 (suppl 1):S149-58

8 Jackson R, Stewart A, Beaglehole R. Trends in coronary heart disease mortality and morbidity in Auckland, New Zealand, 1974-1986. Int $\mathcal{F}$ Epidemiol 1990;19:279-83.

9 La-Vecchia C, Levi F, Negri E, et al. Trends in mortality from coronary heart and cerebrovascular disease in
Switzerland, 1969-87. Soz Praventivmed 1991;36:18-24.

10 Sverre JM. Secular trends in coronary heart disease mortality in Norway, 1966-1986. Am f Epidemiol 1993;

11 Yarnell JWG, Limb ES, Evans AE. Trends in cardiovascular mortality in industrialised countries since 1950: are there any hypotheses to fit the data? Cardiovascular Risk Factors any hypotheses to

12 Gillum RF. Trends in acute myocardial infarction and coronary heart disease death in the United States. $f \mathrm{Am}$

13 Osmond C. Coronary heart disease mortality trends in England and Wales, 1952-1991. F Public Health Med 1995; 17:404-10.

14 Wilson A, Siskind V. Coronary heart disease mortality in Australia: is mortality starting to increase among young men? Int $\mathcal{F}$ Epidemiol 1995;24:678-84

15 Joossens JV, Kesteloot H. Mortality trends in the Netherlands and Belgium: closing the gap. Cardiologie 1995;2: $354-60$

16 Gittelsohn a, Senning J. Studies on the reliability of vital and health records: I. Comparison of cause of death and hospital record diagnoses. Am f Public Health 1979;69:680-9.

17 Cameron HM, McGoogan E. A prospective study of 1152 hospital autopsies: I. Inaccuracies in death certification. $\mathcal{f}$ hospital autopsies: I. Inac

18 Stehbens WE. An appraisal of the epidemic rise of coronary heart disease and its decline. Lancet 1987;i:606-11. 
19 Goldacre MJ. Cause-specific mortality: understanding uncertain tips of the disease iceberg. $\mathcal{F}$ Epidemiol Community $91-6$.

20 Van Houte O, Kesteloot H. An epidemiological survey of risk factors for ischaemic heart disease in 42,804 men. I. The serum cholesterol value. Acta Cardiol 1972;27:527-33.
Joossens JV, Vuylsteek K, Brems-Heyns E, et al. The Joossens JV, Vuylsteek K, Brems-Heyns E, et al. The
patterns of food and mortality in Belgium. Lancet 1977;i:1069-72

22 Kornitzer M, De Backer G, Dramaix M, et al. Regional differences in risk factor distributions, food habits and coronary heart disease mortality and morbidity in Belgium. Int $\mathcal{F}$ Epidemiol 1979;8:23-31.

23 Kesteloot H, Bande J, Pille J, et al. Serum lipid distribution and mortality in Belgium. Eur Heart f 1984;5:778-83.

24 Kornitzer M, Bara L. Differences between north and south in coronary risk factors, food habits and mortality in Belgium. Acta Cardiol 1989;44:145-55.

25 WHO MONICA Project. Monica Manual, revised edition. Geneva: Cardiovascular Diseases Unit, WHO, 1990.

26 Tunstall-Pedoe H, Kuulasmaa K, Amouyel P, et al. Myocardial infarction and coronary deaths in the World Health Organisation MONICA project. Circulation 1994;90:583612

27 World Health Organisation. World Health Statistics Annual 1993. Geneva: WHO, 1993.

28 De Henauw S, de Smet P, Aelvoet W, et al. Misclassification of coronary heart disease in mortality statistics. Evidence from the MONICA Ghent-Charleroi study. $f$ Epidemio Community Health 1998;52:513-19.

29 Hammar N, Ahlbom A, Theorell T. Geographical differences in myocardial infarction incidence in eight Swedish counties, 1976-1981. Epidemiology 1992;3:348-55.
30 Bryce C, Curtis S, Mohan J. Coronary heart disease: trends in spatial inequalities and implications for health care planin England. Soc Sci Med 1994;38:677-90.

31 Marmot $M$. Coronary heart disease: rise and fall of a modern epidemic. In: Marmot M, Elliott P, eds. Coronary heart disease epidemiology. From aetiology to public health. Oxford: Oxford University Press, 1992:3-19.

32 McGovern PG, Folsom AR, Sprafka JM, et al. Trends in survival of hospitalized myocardial infarction patients between 1970 and 1985. The Minnesota Heart Survey. Circulation 1992;85:172-9.

33 Dellborg M, Eriksson P, Riha M, et al. Declining hospital mortality in acute myocardial infarction. Eur Heart 7 1994; 15:5-9.

34 Naylor CD, Chen E. Population-wide mortality trends among patients hospitalized for acute myocardial infarction: the Toronto experience, 1981 to $1991 . \mathcal{F} \mathrm{Am}$ Coll Cardiol 1994;24:1431-8.

35 GISSI. Gissi-3: effects of lisinopril and transdermal glyceryl trinitrate singly and together on 6-week mortality and ventricular function after acute myocardial infarction. Lancet 1994;343:1115-22.

36 The Gusto Investigators. An international randomized trial comparing four thrombolytic strategies for acute myocardial infarction. N Engl f Med 1993;329:673-82.

37 Collins R, Peto R, Flather M, et al. ISIS-4: a randomized factorial trial assessing early oral captopril, oral mononitrate and intravenous magnesium-sulfate in 58,050 patients with suspected acute myocardial infarction. Lancet 1995;345:669-85.

38 Romo M. Factors related to sudden death in acute ischemic disease. A community study in Helsinki. Acta Med Scand 1973;suppl 547. 